\title{
Diffraction and single-crystal elastic constants of Inconel 625 at room and elevated temperatures determined by neutron diffraction
}

\author{
Zhuqing Wang ${ }^{1}$, Alexandru D. Stoica ${ }^{2}$, Dong $\mathrm{Ma}^{2 *}$, Allison M. Beese ${ }^{{ }^{*}}$ \\ ${ }^{1}$ Department of Materials Science and Engineering, Pennsylvania State University, University \\ Park, PA, 16802, USA, *amb961@psu.edu \\ ${ }^{2}$ Chemical and Engineering Materials Division, Neutron Sciences Directorate, Oak Ridge \\ National Laboratory, Oak Ridge, Tennessee 37831, USA, *dongma@ornl.gov
}

\begin{abstract}
In this work, diffraction and single-crystal elastic constants of Inconel 625 have been determined by means of in situ loading at room and elevated temperatures using time-of-flight neutron diffraction. Theoretical models proposed by Voigt, Reuss, and Kroner were used to determine single-crystal elastic constants from measured diffraction elastic constants, with the Kroner model having the best ability to capture experimental data. The magnitude of singlecrystal elastic moduli, computed from single-crystal elastic constants, decreases and the single crystal anisotropy increases as temperature increases, indicating the importance of texture in affecting macroscopic stress at elevated temperatures. The experimental data reported here are of great importance in understanding additive manufacturing of metallic components, in which diffraction elastic constants are required for computing residual stresses from residual lattice strains measured using neutron diffraction, which can be used to validate thermo-mechanical models of additive manufacturing, while single-crystal elastic constants can be used in crystal plasticity modeling, for example, to understand mechanical deformation behavior of additively manufactured components.
\end{abstract}




\section{Keywords}

Diffraction elastic constants; Single-crystal elastic constants; Inconel 625; Neutron diffraction; Superalloys; Additive manufacturing 


\section{Introduction}

Nickel-base superalloys, such as Inconel 625, Inconel 718, and Waspaloy, have excellent mechanical properties and corrosion resistance, especially at high temperature [1-4]. The production of nickel-base superalloy components involves mechanical and thermal processing, which may introduce strain gradients or thermal gradients, which could in turn result in the development of residual stresses. Mechanical processes that introduce residual stresses include traditional thermomechanical manufacturing like rolling and forging $[5,6]$ and post processing methods like machining [7,8], grinding [7,9], and shot peening $[10,11]$. Thermal processes that introduce residual stresses include manufacturing processes that involve rapid solidification of materials such as welding [12-14] and additive manufacturing (AM) [15,16], as well as post processing heat treatment followed by quenching [7,17]. Mechanically generated residual stresses result from non-uniform plastic deformation, wherein compressive or tensile residual stresses are introduced on the surface of component by local plastic deformation [7]. Thermally generated residual stresses result from non-uniform heating and cooling, or thermal treatments with mechanical constraints [7]. For example, in welding and AM, residual stresses build up from the contraction of melt pool during cooling [12-16]. For materials being subjected to heat treatment followed by quenching, the outer surface cools more rapidly than the inner core, resulting in compressive residual stresses on the surface, balanced by tensile stresses in the bulk of the component. Residual stresses may lead to distortions of components, which result in geometries that deviate from their design, and may introduce micro-cracks and local yielding within the component, which will impact the component's mechanical performance $[15,18]$. Therefore, it is important to be able to accurately measure and predict residual stresses during 
manufacturing and post processing of materials in order to combat them, or account for them in design.

Here, we focus on nickel-base superalloys produced by AM. AM can be used to fabricate complicated near-net shape nickel-base superalloy components that cannot be fabricated through traditional casting or subtractive machining methods; thus researchers are investigating the possibility of fabricating solid solution strengthened Inconel 625 through AM [19-21] . Current obstacles in AM of Inconel 625 include the expense, due to the high initial cost of the powder feedstock and the fact that the number of times unused powder can be recycled is an open area of research [22-24]. Additionally, during AM, significant residual stresses are built up due to the complex thermal cycles - specifically, due to the material contraction as the melt pool solidifies and the additional contraction of the material during cooling $[15,16]$. In order to mitigate these stresses, thermomechanical modeling can be used to model the additive manufacturing process, predict the stress buildup and resulting distortion during fabrication, and modify the build process to minimize or counteract these stresses and distortion $[16,18,25]$. However, the prediction of residual stresses using thermomechanical models requires validation of these models. One way to measure residual stresses is using neutron diffraction, which requires grain orientation dependent or $h k l$-specific diffraction elastic constants (DECs) to convert the measured $h k l$-specific lattice strains to macroscopic residual stresses [12,15,26,27].

Diffraction elastic constants, such as Young's modulus, Ehkl, and Poisson's ratio, vhkl, describe the relationship between $h k l$-specific elastic lattice strains measured using neutron diffraction and applied macroscopic stress for a polycrystalline material. DECs can be determined by uniaxially loading the material in the elastic regime, and measuring each $h \mathrm{kl}$ specific lattice strain responses to the applied macroscopic stresses in the loading and transverse 
directions simultaneously using neutron diffraction. For a highly anisotropic material like a nickel-base superalloy, at a given applied macroscopic stress, the stress and strain are distributed non-uniformly among differently oriented grains with respect to the loading direction. The $h k l$ specific orientated grains have their own intrinsic stiffness, single-crystal elastic moduli $E_{h k l}, S C$, defining the constitutive relationship between local stress and strain in a $h k l$-specific orientated grain or single crystal. The direction dependent single-crystal elastic constants comprise a $4^{\text {th }}$ order stiffness tensor, $c_{i j k l}$, or compliance tensor, $s_{i j k l}$; these tensors can be expressed as 6 x 6 matrices, $c_{i j}$ or $s_{i j}$, using Voigt notation. Therefore, materials with strong texture, such as additively manufactured Inconel 625, have a different macroscopic Young's modulus, meaning different macroscopic stress for a given applied elastic strain compared to isotropic or weakly textured materials, resulting in different diffraction elastic constants between textured and isotropic materials [28]. A study conducted by Tayon et al. [29] also showed macroscopic Young's modulus depended on the orientation of highly textured Inconel 718 specimens made by AM. They used electron backscatter diffraction (EBSD) data and an Orientation Imaging Microscopy (OIM) software to estimate macroscopic Young's modulus in specimens with different orientations, in which single-crystal elastic constants were necessary inputs for the OIM software. As such, knowing single-crystal elastic constants and elastic anisotropy is essential in understanding anisotropic deformation behaviors, especially at elevated temperatures where the anisotropic factor increases significantly. In addition, single-crystal elastic constants are used to provide grain-level constitutive information in crystal plasticity modeling, to calculate elastic energy for understanding dislocation interactions, and to determine the stability of phases to understand the occurrence of phase transformation [30-32]. 
Single-crystal elastic constants can be measured by different methods. Alers et al. and Kanrar et al. $[33,34]$ determined $c_{i j}$ in Fe-Ni alloys using acoustic methods, in which the speed of ultrasonic waves propagating through single crystals was measured. However, this method is limited by the purity and size of single crystals, the difficulty in fabricating single crystals, and the availability and accuracy of sensors used to detect ultrasonic waves at high temperatures or pressures [35]. Single-crystal elastic constants can also be determined using in situ diffraction methods during mechanical loading of polycrystalline materials at prescribed temperatures or pressures. Aba-Perea et al. [4] measured $E_{h k l}$ and $v h k l$ using neutron diffraction in Inconel 718 and plotted 1/Ehkl and - $-v_{h k l} / E_{h k l}$ versus direction cosines of (hkl) to determine the linear interpolation coefficients for single-crystal elastic constants, rather than $c_{i j}$. Further, no literature has reported diffraction elastic constants or single-crystal elastic constants of nickel-base alloys, in particular, Inconel 625 , at elevated temperatures.

The present study focuses on measuring $h k l$-specific DECs and determining single-crystal elastic constants, $c_{i j}$, at room and high temperatures in Inconel 625 (IN625), a face-centered cubic (fcc) material that is widely used for additive manufacturing. Macroscopic stress and $h k l$ specific lattice strain measured by in situ neutron diffraction of IN625 upon elastic loading were used to determine the DECs, $E_{h k l}$ and $v_{h k l}$, which were then used to calculate $c_{i j}$ and the singlecrystal elastic moduli, Ehkl, SC using a theoretical model proposed by Kroner [36]. The macroscopic elastic modulus, EM, which describes macroscopic stress and strain relationships in isotropic materials, was measured from the experiments and also computed from $c_{i j}$. The comparison between the measured and computed $\mathrm{E}_{\mathrm{M}}$ can be used to assess the accuracy of the selected model. 


\section{Materials and Methods}

We investigated conventionally rolled and annealed IN625 and IN625 deposited using directed energy deposition (DED). In powder-based, laser-based DED AM, powder is delivered through nozzles to a molten pool, on a substrate or layer below, produced by a laser beam [3740]. A $101 \mathrm{~mm}$ long, $28 \mathrm{~mm}$ tall, $7 \mathrm{~mm}$ thick IN625 wall was deposited, using pre-alloyed IN625 powder, onto an annealed IN625 (AN IN625) substrate (ASTM B-443 Grade 1 [41]). A laser power of $2 \mathrm{~kW}$, scanning speed of $10.6 \mathrm{~mm} / \mathrm{s}$, powder feed rate of $16 \mathrm{~g} / \mathrm{min}$, and argon gas flow rate of $9.4 \mathrm{~L} / \mathrm{min}$ were used to deposit the IN625 wall by additive manufacturing (AM IN625) [16]. Energy dispersive spectroscopy (EDS) was used to determine the chemical composition of annealed and AM IN625, with the measured compositions given in Table 1. EDS analysis and scanning electron microscope (SEM) images indicated that AN IN625 consisted of a small amount ( $<1 \mathrm{vol} \%)$ of carbides rich in $\mathrm{Nb}$, Mo, and Ti distributed in an fcc $\gamma$ matrix, and AM IN625 consisted of a small amount ( $<2$ vol\%) of Nb- and Mo- rich carbides and Laves phase distributed in an fcc $\gamma$ matrix [42]. These primary and secondary phases in AN and rapidly solidified IN625 are consistent with the literature [19-21,43,44].

Table 1. Elemental composition in wt.\% of AN IN625 and AM IN625 measured by EDS.

\begin{tabular}{|c|c|c|c|c|c|c|c|c|c|c|}
\hline & $\mathrm{Ni}$ & $\mathrm{Cr}$ & $\mathrm{Mo}$ & $\mathrm{Fe}$ & $\mathrm{Nb}$ & $\mathrm{Co}$ & $\mathrm{Mn}$ & $\mathrm{Si}$ & $\mathrm{Ti}$ & $\mathrm{Al}$ \\
\hline $\begin{array}{c}\mathrm{AN} \\
\text { IN625 }\end{array}$ & 59.2 & 22.3 & 9.5 & 4.7 & 3.5 & 0.4 & 0.3 & 0.3 & 0.1 & 0.2 \\
\hline $\begin{array}{c}\text { AM } \\
\text { IN625 }\end{array}$ & 60.2 & 23.5 & 8.7 & 4.6 & 2.3 & 0.1 & 0.4 & 0.4 & 0 & 0 \\
\hline
\end{tabular}

To measure mechanical behavior of IN625 under compression, $5 \mathrm{~mm}$ diameter and $10 \mathrm{~mm}$ long cylindrical specimens were extracted from both IN625 made by AM and the annealed substrate. Compression tests at room temperature, $600{ }^{\circ} \mathrm{C}$, and $700{ }^{\circ} \mathrm{C}$ at a strain rate of $3 \times 10^{-5}$ were performed with in situ neutron diffraction using the VULCAN instrument at the Spallation 
Neutron Source at Oak Ridge National Laboratory $[45,46]$. Two detector banks in VULCAN allowed for collecting diffraction spectra simultaneously from grains whose lattice planes (hkl) were perpendicular to two orthogonal scattering vectors, which were along and perpendicular to the loading axis [47]. The $h k l$-dependent lattice strains $\left(\varepsilon_{\mathrm{hkl}}\right)$ resulting from the applied compressive load were measured by in situ neutron diffraction as $\varepsilon_{h k l}=\frac{d_{h k l}-d_{h k l}^{0}}{d_{h k l}^{0}}$, where $d_{h k l}$ is the lattice spacing of the (hkl) plane during deformation, and $d_{h k l}^{0}$ the stress-free lattice spacing of the (hkl) plane. The diffraction elastic moduli, $E_{h k l}$, define the constitutive relationship between the macroscopic true stress and the lattice strains under uniaxial loading, and the diffraction elastic Poisson's ratios, vhkl, describe the ratio of the lattice strain expansion in the transverse direction with respect to the lattice strain compression in the loading direction.

Single-crystal elastic constants can be homogenized into diffraction elastic constants and isotropic macroscopic elastic constants using theoretical models. The most widely used models are those proposed by Voigt [48], Reuss [49], and Kroner [36]. The Voigt model assumes that a homogeneous strain is applied to all grains during loading, but fails to satisfy equilibrium at grain boundaries. The Reuss model assumes a homogeneous stress is applied to all grains, but fails to satisfy continuity of strains at grain boundaries. However, due to their simplicity, these two models are still used to estimate upper and lower bounds for the diffraction and isotropic macroscopic elastic constants [50]. In contrast to the Voigt and Reuss models, the Kroner model accounts for stress and strain variations among grains [51]. In all three models, the grain orientation dependent diffraction elastic constants, including Young's moduli, $E_{h k l}$, Poisson's ratios, $v_{h k l}$, and shear moduli, $G_{h k l}$, are expressed as a function of $c_{i j}$ or $s_{i j}$ and the direction 
cosines of $<\mathrm{hkl}>$. When all orientations are considered, the isotropic macroscopic elastic moduli can also be computed from $c_{i j}$ or $s_{i j}[52]$.

In IN625, an fcc material, there are only three independent $c_{i j}$ constants: $c_{11}, c_{12}$, and $c_{44}$. The diffraction shear moduli in Voigt's model (Gv) and Reuss' model $\left(\mathrm{G}_{\mathrm{R}}\right)$ are defined as [52]:

$$
\begin{aligned}
& G_{V}=\frac{1}{5}(2 \mu+3 \eta) \\
& G_{R}=\frac{\mu \eta}{\left[\eta+3(\mu-\eta) A_{h k l}\right]}
\end{aligned}
$$

where Ahkl defines the direction cosines of $<\mathrm{hkl}>$, and is given as $A h k l=\left(h^{2} k^{2}+k^{2} l^{2}+l^{2} h^{2}\right) /\left(h^{2}+k^{2}\right.$ $\left.+l^{2}\right)^{2}$, which is equal to $1 / 5$ if averaging over all orientations; $\mu$ and $\eta$ are shear moduli expressed as $\mu=\left(\mathrm{c}_{11}-\mathrm{c}_{12}\right) / 2$ and $\eta=\mathrm{c}_{44}$, where $\mu=\eta$ in isotropic materials.

In the Kroner model, the diffraction shear modulus, GK, is defined as [52]:

$$
G_{K}^{3}-\alpha G_{K}^{2}-\beta G_{K}-\gamma=0
$$

where $\alpha, \beta$, and $\gamma$ are given as:

$$
\begin{aligned}
& \alpha=\frac{1}{5}(2 \mu+3 \eta)-\frac{3}{8}\left\{3 K+4\left[\eta+3(\mu-\eta) A_{h k l}\right]\right\} ; \\
& \beta=\frac{3}{40}(6 K \mu+9 K \eta+20 \mu \eta)-\frac{3}{4} K\left[\eta+3(\mu-\eta) A_{h k l}\right] ; \gamma=\frac{3}{4} K \mu \eta
\end{aligned}
$$

where $\mathrm{K}$ is the bulk modulus, which is equal to $\left(\mathrm{c}_{11}+2 \mathrm{c}_{12}\right) / 3$. When $A_{h k l}$ equals $1 / 5$, the diffraction shear moduli in Eqn. (3) become the isotropic macroscopic shear modulus, GM. Then, the isotropic macroscopic Young's modulus, Ем, can be calculated as:

$$
E_{M}=\frac{9 G_{M} K}{G_{M}+3 K}
$$

The $h k l$-specific reciprocal diffraction elastic constants $1 / E_{h k l}$ and $v_{h k l} / E_{h k l}$ can be calculated from the following set of equations: 


$$
\frac{1}{9 K}-\frac{1}{6 G_{h k l}}=-\frac{v_{h k l}}{E_{h k l}} ; \frac{1}{G_{h k l}}=2\left(\frac{1}{E_{h k l}}+\frac{v_{h k l}}{E_{h k l}}\right)
$$

In the present study, $1 / E_{h k l}$ and $v_{h k l} / E_{h k l}$ were measured using in situ neutron diffraction, which are fitted using the Kroner model [Eqn (6)]. Single crystal elastic constants, $c_{i j}$, were used as free parameters in the fitting and eventually determined by minimizing the value of a cost function, taken here to be:

$$
\chi^{2}=\sum_{i=1}^{n}\left(\left(1 / E_{h k l}\right)_{\mathrm{exp}, i}-\left(1 / E_{h k l}\right)_{\bmod e l, i}\right)^{2} / e_{1, i}^{2}+\left(\left(v_{h k l} / E_{h k l}\right)_{\exp , i}-\left(v_{h k l} / E_{h k l}\right)_{\bmod e l, i}\right)^{2} / e_{2, i}^{2}
$$

where $\mathrm{n}$ is the number of (hkl) diffraction planes used to fit the models, $\left(1 / E_{h k l}\right)_{\text {exp }}$ and $\left(v_{h k l} / E_{h k l}\right)_{\text {exp }}$ are determined experimentally from neutron diffraction, $e_{1}$ and $e_{2}$ are the corresponding experimental errors, and $\left(1 / E_{h k l}\right)_{m o d e l}$ and $\left(v_{h k l} / E_{h k l}\right)_{m o d e l}$ are calculated using the Kroner model.

The single-crystal elastic moduli, $E_{h k l}, S C$, are calculated using:

$$
\begin{aligned}
\frac{1}{E_{h k l, S C}} & =s_{11}-2\left(s_{11}-s_{12}-\frac{1}{2} s_{44}\right) A_{h k l} \\
= & \frac{c_{11}+c_{12}}{\left(c_{11}-c_{12}\right)\left(c_{11}+2 c_{12}\right)}-2\left(\frac{1}{\left(c_{11}-c_{12}\right)}-\frac{1}{2 c_{44}}\right) A_{h k l}
\end{aligned}
$$

\section{Results and Discussion}

Neutron diffraction patterns from the axial (or loading) direction in annealed (AN) IN625 at increments of compressive load at room temperature are shown in Fig. 1, which shows that the peaks shift during loading, from which we can calculate lattice strain. The strong texture in AM IN625 affects the macroscopic stress distribution at a given strain, which then affects the measured diffraction elastic constants, so data from isotropic AN IN625 are used to calculate $c_{i j}$. As the secondary phases in AN and AM IN625 were less than 2 vol. \%, they did not have an 
effect on the diffraction patterns and lattice strain measurements of the fcc $\gamma$ matrix. True stress as a function of axial and transverse lattice strains in AN IN625 is plotted to calculate the diffraction elastic constants $E_{h k l}$ and $v h k l$ at room and elevated temperatures as shown in Fig. 2. Single-crystal elastic constants, $c_{i j}$, were quantified using the Kroner model, by minimizing the cost function in Eqn. (7). Using the computed values of $c_{i j}$ and Eqns. (5) and (8), the theoretical values of $E_{M}$ and $E_{h k l, S C}$ were calculated. Since the $E_{M}$ values were also measured from experiments, a comparison between the measured and theoretically computed $\mathrm{E}_{\mathrm{M}}$ values obtained from the Kroner model can ascertain the applicability of the model. For example, at room temperature, EM was measured to be $207.5 \mathrm{GPa}$ and calculated to be $209.3 \mathrm{GPa}$ using the Kroner model, resulting in a $0.9 \%$ difference, indicating that the Kroner model works well for AN IN625. All the measured $E_{h k l}, v_{h k l}$, and $E_{M}$, and computed $E_{h k l, S C}, c_{i j}$, and $E_{M}$ at room and elevated temperatures are shown in Table 2. The calculated $c_{i j}$ values using the Kroner model at room temperature are in line with those reported in literature [53]. 


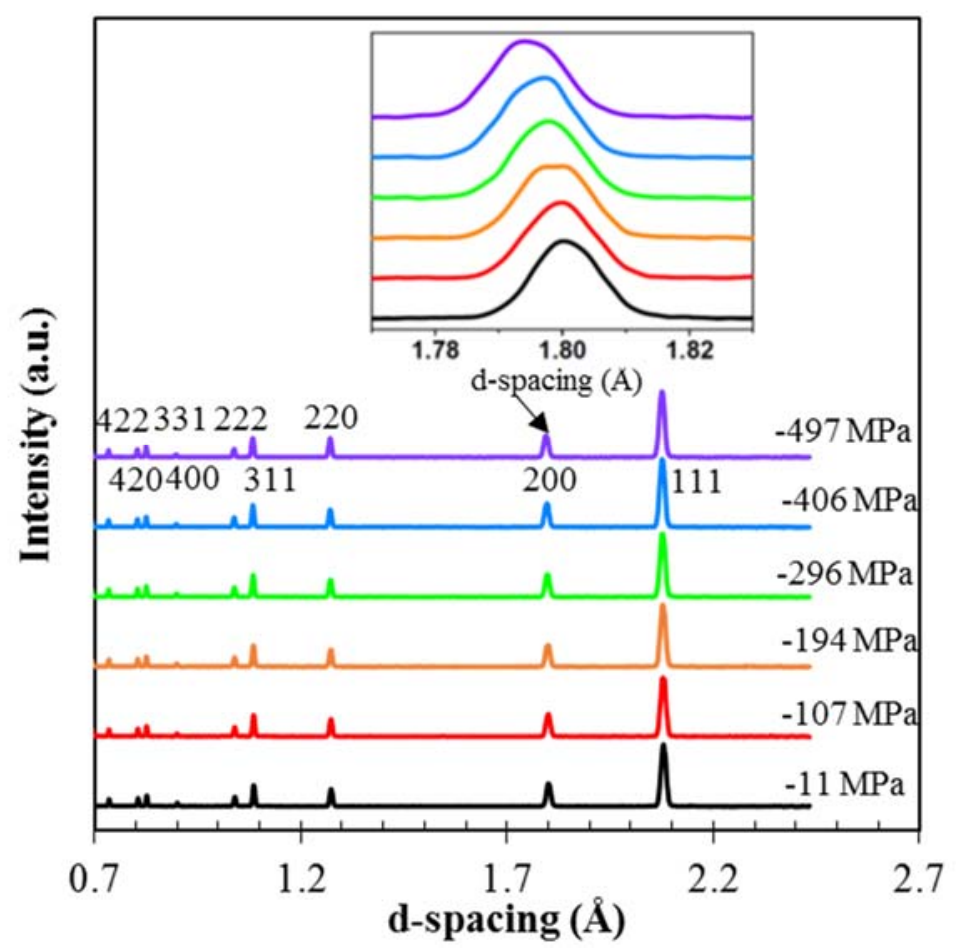

Fig. 1. Neutron diffraction patterns from the axial/loading direction (bank 1) for annealed IN625 during compressive loading at room temperature. The inset shows the shifting of (200) with applied load. 
(a)

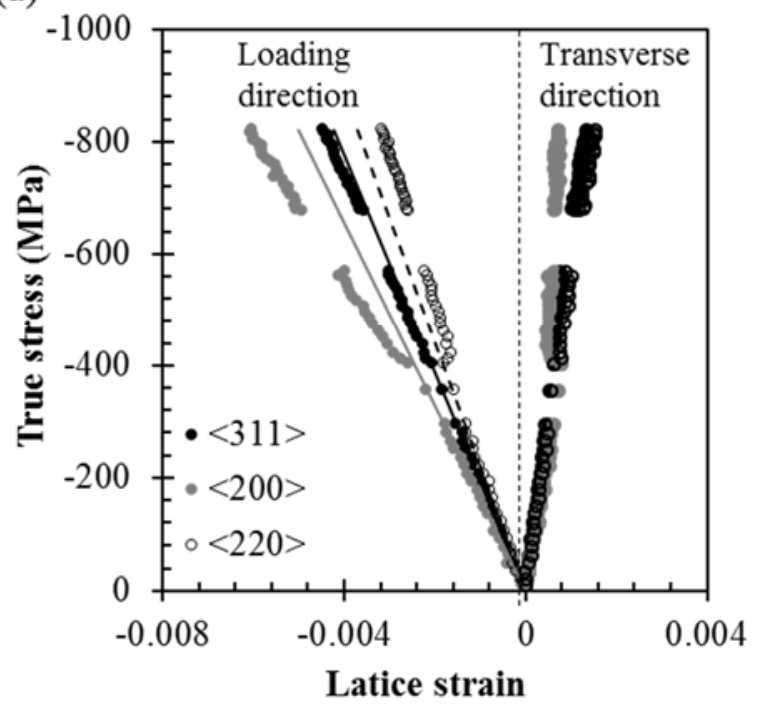

(b)

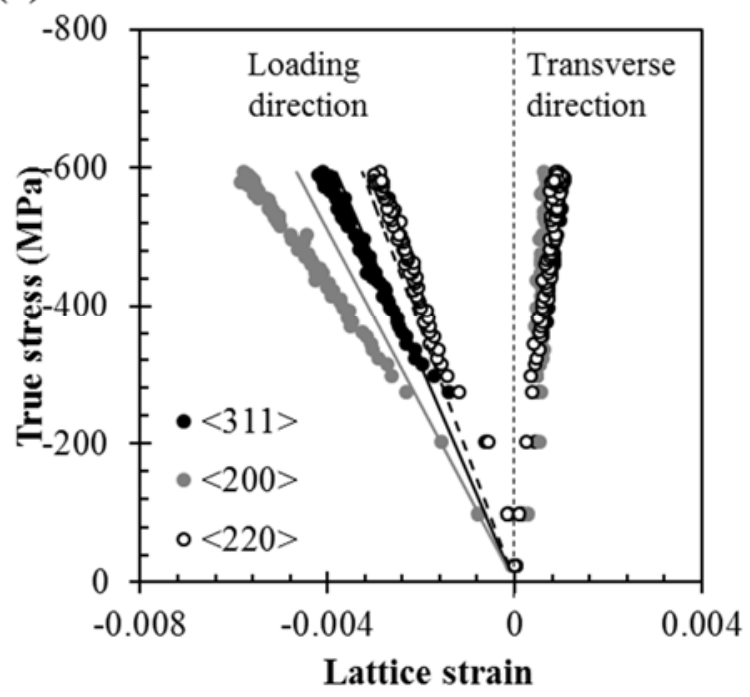

(c)

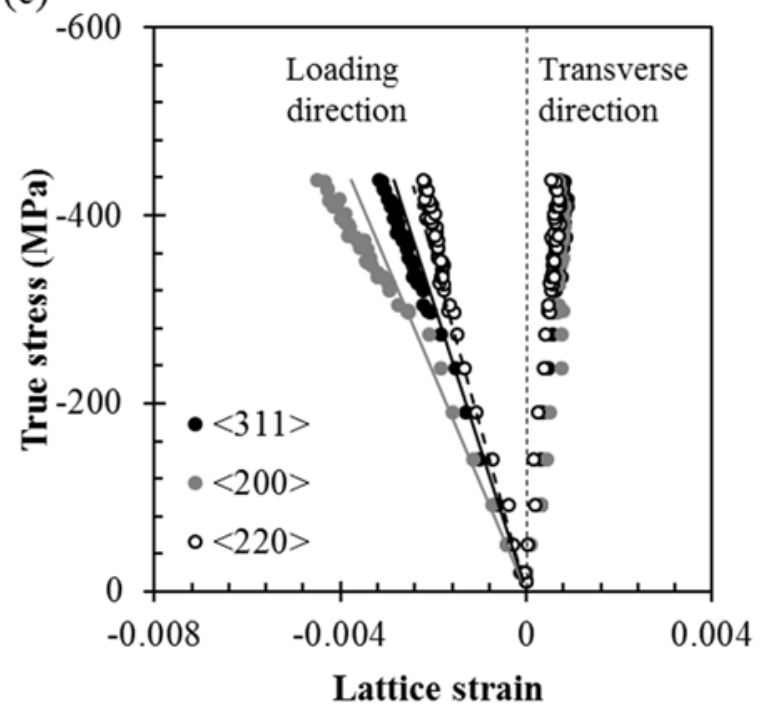

Fig. 2. Macroscopic true stress versus lattice strain in loading and transverse directions for annealed IN625 deformed at (a) room temperature, (b) $600{ }^{\circ} \mathrm{C}$, and (c) $700{ }^{\circ} \mathrm{C}$. 
Table 2. Materials properties in AM IN625 and AN IN625.

\begin{tabular}{|c|c|c|c|c|c|}
\hline$<h k l>$ & $A_{\mathrm{hkl}}$ & $\begin{array}{c}E_{\mathrm{hkl}, \mathrm{AN}} \\
\mathrm{RT}(\mathrm{GPa})\end{array}$ & $\begin{array}{l}(v / E)_{\mathrm{hkl}, \mathrm{AN}} \\
\mathrm{RT}\left(\mathrm{TPa}^{-1}\right)\end{array}$ & $\begin{array}{c}E_{\mathrm{hkl}, \mathrm{AM}} \\
\mathrm{RT}(\mathrm{GPa})\end{array}$ & $\begin{array}{c}E_{\mathrm{hkl}, \mathrm{SC}} \\
\mathrm{RT}(\mathrm{GPa})\end{array}$ \\
\hline 200 & 0.00 & 163.8 & 2.13 & 123.4 & 120.5 \\
\hline 311 & 0.16 & 193.8 & 1.57 & 156.3 & 166.6 \\
\hline 420 & 0.16 & 198.2 & 1.69 & 168.6 & 167.8 \\
\hline 220 & 0.25 & 221.6 & - & 209.9 & 215.3 \\
\hline 422 & 0.25 & 223.1 & 1.38 & - & 215.3 \\
\hline 331 & 0.27 & 240.2 & 1.25 & 219.1 & 233.0 \\
\hline 111 & 0.33 & 250.6 & 1.19 & 276.7 & 291.7 \\
\hline \multirow{2}{*}{ EM } & Experiment & 207.5 & & 152.0 & \\
\hline & Kroner & 209.3 & & & \\
\hline$<h k l>$ & $A_{\mathrm{hkl}}$ & $\begin{array}{c}E_{\mathrm{hkl}, \mathrm{AN}} 600^{\circ} \mathrm{C} \\
(\mathrm{GPa})\end{array}$ & $\begin{array}{c}(v / E)_{\mathrm{hkl}, \mathrm{AN}} \\
600^{\circ} \mathrm{C}\left(\mathrm{TPa}^{-1}\right)\end{array}$ & $\begin{array}{c}E \mathrm{hkl}, \mathrm{AM} \\
600^{\circ} \mathrm{C}(\mathrm{GPa})\end{array}$ & $\begin{array}{c}E_{\mathrm{hl} l, \mathrm{SC}} \\
600^{\circ} \mathrm{C}(\mathrm{GPa})\end{array}$ \\
\hline 200 & 0.00 & 127.1 & 2.92 & 100.7 & 87.4 \\
\hline 311 & 0.16 & 156.1 & 2.14 & 127.7 & 126.5 \\
\hline 420 & 0.16 & 157.3 & - & 128.4 & 127.5 \\
\hline 220 & 0.25 & 183.1 & 1.72 & 161.2 & 172.0 \\
\hline 422 & 0.25 & 180.7 & - & - & 172.0 \\
\hline 331 & 0.27 & 194.5 & - & - & 189.4 \\
\hline 111 & 0.33 & 219.4 & 1.54 & - & 254.0 \\
\hline \multirow{2}{*}{$\mathrm{E}_{\mathrm{M}}$} & Experiment & 172.4 & & 113.0 & \\
\hline & Kroner & 171.1 & & & \\
\hline$<h k l>$ & $A_{\mathrm{hkl}}$ & $\begin{array}{c}E_{\mathrm{hkl}, \mathrm{AN}} \\
700^{\circ} \mathrm{C}(\mathrm{GPa})\end{array}$ & $\begin{array}{c}(v / E) \mathrm{hkl}, \mathrm{AN} \\
700^{\circ} \mathrm{C}\left(\mathrm{TPa}^{-1}\right)\end{array}$ & & $\begin{array}{c}E_{\mathrm{hl} l, \mathrm{SC}} \\
700^{\circ} \mathrm{C}(\mathrm{GPa})\end{array}$ \\
\hline 200 & 0.00 & 116.4 & 3.26 & & 79.2 \\
\hline 311 & 0.16 & 154.6 & 2.20 & & 116.4 \\
\hline 420 & 0.16 & 154.4 & 2.29 & & 117.4 \\
\hline 220 & 0.25 & 177.4 & 1.69 & & 161.3 \\
\hline 422 & 0.25 & 169.9 & - & & 161.3 \\
\hline 331 & 0.27 & 174.4 & 1.98 & & 179.3 \\
\hline 111 & 0.33 & 202.9 & 1.57 & & 246.4 \\
\hline \multirow{2}{*}{ ЕM } & Experiment & 165.0 & & & \\
\hline & Kroner & 163.5 & & & \\
\hline SC constants & $c_{11}(\mathrm{GPa})$ & $c_{12}(\mathrm{GPa})$ & $c_{44}(\mathrm{GPa})$ & $Z$ & \\
\hline RT [53] & 234.6 & 145.4 & 126.2 & 2.8 & \\
\hline RT (Present) & 243.3 & 156.7 & 117.8 & 2.7 & \\
\hline $600{ }^{\circ} \mathrm{C}$ (Present) & 214.8 & 153.1 & 101.1 & 3.3 & \\
\hline $700^{\circ} \mathrm{C}$ (Present) & 205.2 & 149.3 & 99.3 & 3.6 & \\
\hline
\end{tabular}

- Data not available due to weak peaks;

RT-Room temperature;

SC-Single crystal; 
Reciprocal diffraction elastic constants $1 / E_{h k l}$ and $v_{h k l} / E_{h k l}$ calculated by Voigt, Reuss, and Kroner models are plotted as a function of $A_{h k l}$ in Fig. 3, together with experimental data. In all three models, reciprocal diffraction elastic constants were computed using $c_{i j}$ from the Kroner model. At room and elevated temperatures, the Kroner model fits the experimental data very well, which are significantly different from those predicted with the Voight and Reuss models.
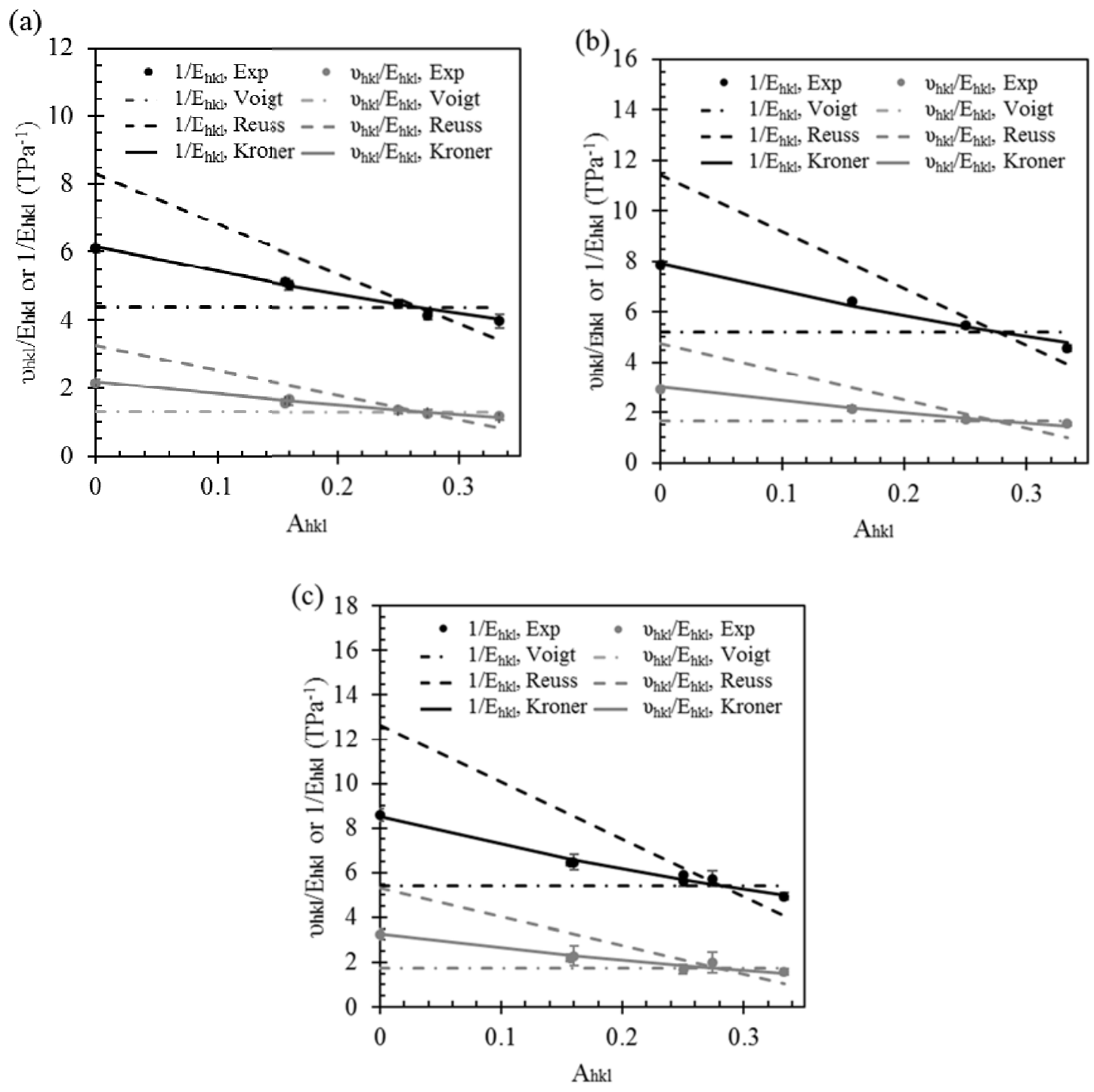

Fig. 3. Reciprocal diffraction elastic constants, $v_{h k} / E_{h k l}$ and $1 / E_{h k l}$ as a function of $A_{h k l}$. The Kroner model is used to fit experimental data (symbols), in comparison with those predicted by the Reuss and Voigt models, and plotted as solid lines for annealed IN625 deformed at (a) room temperature, (b) $600{ }^{\circ} \mathrm{C}$, and (c) $700{ }^{\circ} \mathrm{C}$. 
The surfaces of $E_{h k l, S C}$ as a function of three orthogonal axes [001], [010], and [100] are plotted at room and elevated temperatures in Fig. 4. The two plots have similar shapes, where $<111>$ is the stiffest orientation, and $<100>$ is the most compliant orientation. As the temperature increases, the magnitude of $E_{h k l, S C}$ decreases. The Zener anisotropy ratio, Z, is defined for cubic systems as $2 c_{44} /\left(c_{11}-c_{12}\right)$, and it is equal to 1 in isotropic systems. The anisotropy ratio is 2.7 at room temperature, increases to 3.3 at $600{ }^{\circ} \mathrm{C}$ and to 3.6 at $700{ }^{\circ} \mathrm{C}$, indicating an increase in anisotropy with temperature, which is also illustrated in Fig. 4. 
(a)

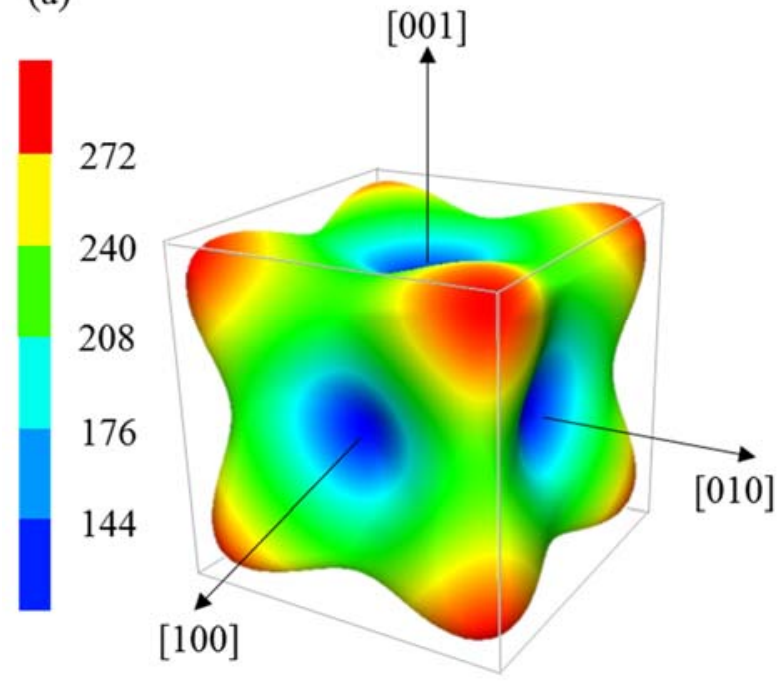

(b)

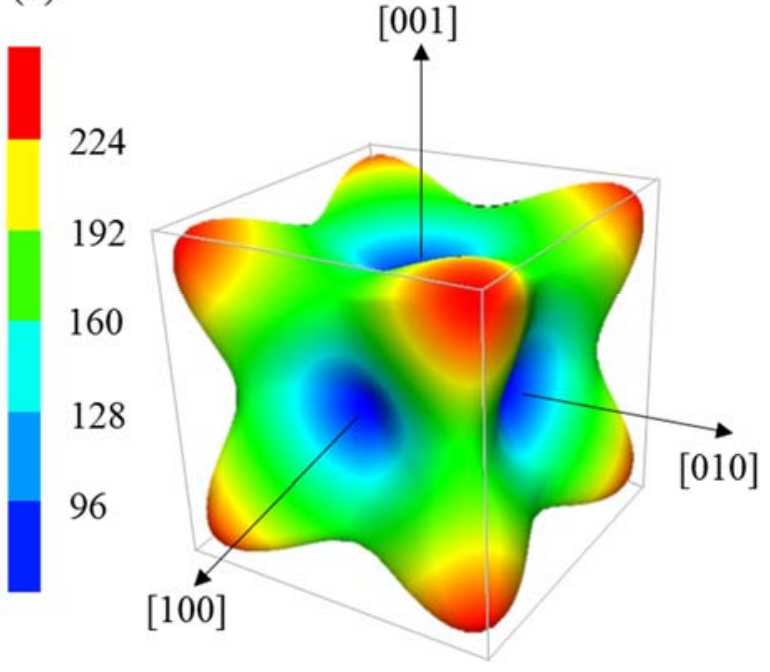

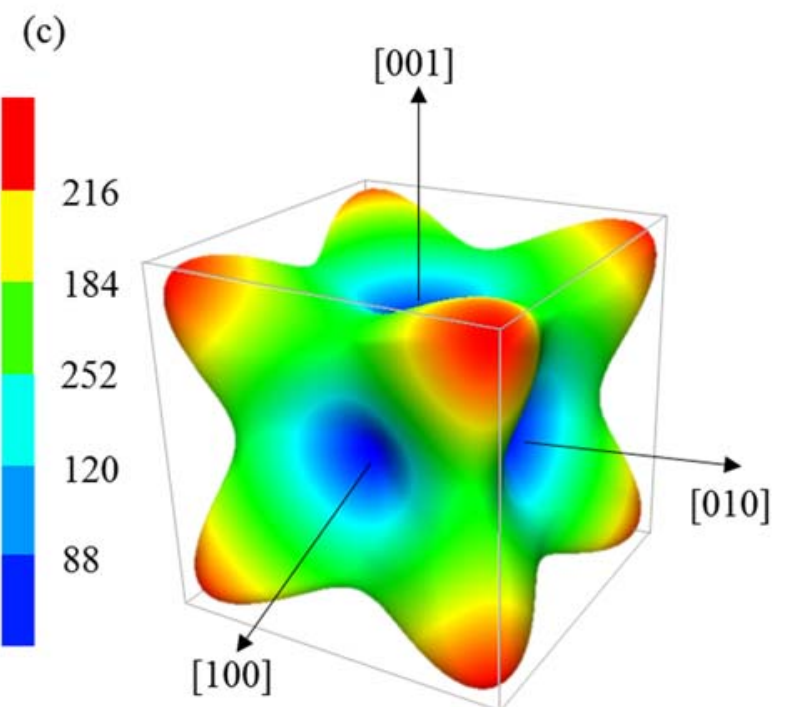

Fig. 4. Contours of single-crystal elastic modulus, $E_{h k l}$, SC, for AN IN625 at (a) room temperature, (b) $600^{\circ} \mathrm{C}$, and (c) $700^{\circ} \mathrm{C}$.

\section{Summary and Conclusions}

In summary, this work reports diffraction and single-crystal elastic constants, $c_{i j}$, of Inconel 625 at room and elevated temperatures. These are useful for understanding a variety of thermomechanical properties of additively manufactured components and mechanical behaviors of conventional materials. Diffraction elastic constants $E_{h k l}$ and $v h k l$ were measured using in situ 
neutron diffraction, and the $c_{11}, c_{12}$, and $c_{44}$ were determined using the Kroner model and measured $E_{h k l}$ and $v_{h k l}$. The macroscopic elastic modulus, $E_{M}$, and single-crystal elastic moduli, $E_{h k l}, S C$, were computed using the $c_{i j}$ values. The primary findings of this paper are as follows:

- The computed $c_{i j}$ are in line with those reported in literature at room temperature, while the $c_{i j}$ at $600{ }^{\circ} \mathrm{C}$ and $700{ }^{\circ} \mathrm{C}$ reported herein are missing in current literature. The values of the isotropic macroscopic modulus, $\mathrm{E}_{\mathrm{M}}$, at different temperatures that are theoretically computed using $E_{h k l}$ and $v_{h k l}$ measured from neutron diffraction are in good agreement with the experimentally measured values, indicating the applicability of the Kroner model for this material.

- As the temperature increases, the magnitude of $E_{h k l}, s C$ decreases and the Zener anisotropy ratio increases, indicating that texture plays an increasingly important role in affecting the macroscopic stress with increasing temperature. Temperatures during AM processing fluctuate from above the melting temperature to room temperature during solidification and cooling, indicating the importance of incorporating texture in thermomechanical modeling of AM.

- Thermomechanical models for additive manufacturing are used to describe the buildup of stresses during fabrication, and the resulting distortions in the final part; however, these models require experimental validation, which can be done using neutron diffraction measurements of residual strains. The measured diffraction elastic moduli, $E_{h k l}$, by neutron diffraction are used to convert lattice strain to residual stress measurements.

- Single-crystal elastic constants, $c_{i j}$, are used in crystal plasticity modeling, calculating orientation-dependent Young's modulus to understand single-crystal anisotropy, 
calculating elastic energy to understand dislocation interactions, and determining stability of certain phases. 


\section{Acknowledgments}

The authors gratefully acknowledge the financial support of the National Science Foundation through award number CMMI-1402978. Any opinions, findings, and conclusions or recommendations expressed in this material are those of the authors and do not necessarily reflect the views of the National Science Foundation. AMB acknowledges funding from the Oak Ridge Associated Universities Ralph E. Powe Junior Faculty Enhancement Award. AM-IN625 samples were fabricated at Penn State's Center for Innovative Materials Processing through Direct Digital Deposition (CIMP-3D). A portion of this research at ORNL's Spallation Neutron Source was sponsored by the Scientific User Facilities Division, Office of Basic Energy Sciences, U.S. Department of Energy. Matthew Frost and Harley Skorpenske are acknowledged for their technical support. 


\section{References}

[1] D. Li, Q. Guo, S. Guo, H. Peng, Z. Wu, The microstructure evolution and nucleation mechanisms of dynamic recrystallization in hot-deformed Inconel 625 superalloy, Mater. Des. 32 (2011) 696-705. doi:10.1016/j.matdes.2010.07.040.

[2] A. Thomas, M. El-Wahabi, J.M. Cabrera, J.M. Prado, High temperature deformation of Inconel 718, J. Mater. Process. Technol. 177 (2006) 469-472. doi:10.1016/j.jmatprotec.2006.04.072.

[3] C.-M. Kuo, Y.-T. Yang, H.-Y. Bor, C.-N. Wei, C.-C. Tai, Aging effects on the microstructure and creep behavior of Inconel 718 superalloy, Mater. Sci. Eng. A. 510-511 (2009) 289-294. doi:10.1016/j.msea.2008.04.097.

[4] P.E. Aba-Perea, T. Pirling, P.J. Withers, J. Kelleher, S. Kabra, M. Preuss, Determination of the high temperature elastic properties and diffraction elastic constants of Ni-base superalloys, Mater. Des. 89 (2016) 856-863. doi:10.1016/j.matdes.2015.09.152.

[5] D. Dye, B.A. Roder, S. Tin, M.A. Rist, J.A. James, M.R. Daymond, Modeling and Measurement of Residual Stresses in a Forged IN718 Superalloy Disc, in: TMS, Warrendale, PA, 2004: pp. 315-322.

[6] A.M. Korsunsky, G.M. Regino, D.P. Latham, H.Y. Li, M.J. Walsh, Residual stresses in rolled and machined nickel alloy plates: Synchrotron X-ray diffraction measurement and three-dimensional eigenstrain analysis, J. Strain Anal. Eng. Des. 42 (2007) 1-12.

[7] F. a Kandil, J.D. Lord, a T. Fry, P. V Grant, A review of residual stress measurement methods, A Guid. to Tech. Sel. NPL, Rep. MATC. 4 (2001) 1-42.

[8] D. Ulutan, B.E. Alaca, I. Lazoglu, Analytical modelling of residual stresses in machining, J. Mater. Process. Technol. 183 (2007) 77-87. 
[9] P.J. Withers, H.K.D.H. Bhadeshia, Residual stress. Part 2 - Nature and origins, Mater.

Sci. Technol. 17 (2001) 366-375. doi:10.1179/026708301101510087.

[10] S. Wang, Y. Li, M. Yao, R. Wang, Compressive residual stress introduced by shot peening, J. Mater. Process. Technol. 73 (1998) 64-73. doi:10.1016/S09240136(97)00213-6.

[11] D. Cai, P. Nie, J. Shan, W. Liu, M. Yao, Y. Gao, Precipitation and residual stress relaxation kinetics in shot-peened Inconel 718, J. Mater. Eng. Perform. 15 (2006) 614617.

[12] D. Thibault, P. Bocher, M. Thomas, M. Gharghouri, M. Côté, Residual stress characterization in low transformation temperature $13 \% \mathrm{Cr}-4 \% \mathrm{Ni}$ stainless steel weld by neutron diffraction and the contour method, Mater. Sci. Eng. A. 527 (2010) 6205-6210. doi:10.1016/j.msea.2010.06.035.

[13] J.R. Cho, B.Y. Lee, Y.H. Moon, C.J. Van Tyne, Investigation of residual stress and post weld heat treatment of multi-pass welds by finite element method and experiments, J. Mater. Process. Technol. 155-156 (2004) 1690-1695. doi:10.1016/j.jmatprotec.2004.04.325.

[14] A. Paradowska, J.W.H. Price, R. Ibrahim, T. Finlayson, A neutron diffraction study of residual stress due to welding, J. Mater. Process. Technol. 164-165 (2005) 1099-1105. doi:10.1016/j.jmatprotec.2005.02.092.

[15] R.J. Moat, a. J. Pinkerton, L. Li, P.J. Withers, M. Preuss, Residual stresses in laser direct metal deposited Waspaloy, Mater. Sci. Eng. A. 528 (2011) 2288-2298. doi:10.1016/j.msea.2010.12.010.

[16] E.R. Denlinger, J.C. Heigel, P. Michaleris, T.A. Palmer, Effect of inter-layer dwell time 
on distortion and residual stress in additive manufacturing of titanium and nickel alloys, J. Mater. Process. Technol. 215 (2015) 123-131. doi:10.1016/j.jmatprotec.2014.07.030.

[17] Y. Dahan, S. Noveau, E. Georges, B. Flageolet, Residual stresses in Inconel 718 engine disks, MATEC Web Conf. 14 (2014) 1-6.

[18] P. Mercelis, J.-P. Kruth, Residual stresses in selective laser sintering and selective laser melting, Rapid Prototyp. J. 12 (2006) 254-265. doi:10.1108/13552540610707013.

[19] F. Xu, Y. Lv, Y. Liu, F. Shu, P. He, B. Xu, Microstructural Evolution and Mechanical Properties of Inconel 625 Alloy during Pulsed Plasma Arc Deposition Process, J. Mater. Sci. Technol. 29 (2013) 480-488.

[20] C.C. Silva, H.C. De Miranda, M.F. Motta, J.P. Farias, C.R.M. Afonso, A.J. Ramirez, New insight on the solidification path of an alloy 625 weld overlay, J. Mater. Res. Technol. 2 (2013) 228-237. doi:10.1016/j.jmrt.2013.02.008.

[21] M. Rombouts, G. Maes, M. Mertens, W. Hendrix, Laser metal deposition of Inconel 625: Microstructure and mechanical properties, J. Laser Appl. 24 (2012) 052007. doi:10.2351/1.4757717.

[22] D. Thomas, Costs, benefits, and adoption of additive manufacturing: a supply chain perspective, Int. J. Adv. Manuf. Technol. 85 (2016) 1857-1876. doi:10.1007/s00170-015$7973-6$.

[23] X. Wu, A review of laser fabrication of metallic engineering components and of materials, Mater. Sci. Technol. 23 (2007) 631-640. doi:10.1179/174328407X179593.

[24] P.A. Carroll, P. Brown, F. Ng, R. Scudamore, A.J. Pinkerton, W.U.H. Syed, H.K. Sezer, L. Li, J. Allen, The Effect of Powder Recycling in Direct Metal Laser Deposition on Powder and Manufactured Part Characteristics, in: Proc. AVT-139 Spec. Meet. Cost Eff. 
Manuf. via Net Shape Process., Amsterdam, 2006: pp. 1-10.

[25] E.R. Denlinger, J.C. Heigel, P. Michaleris, Residual stress and distortion modeling of electron beam direct manufacturing Ti-6Al-4V, Proc. Inst. Mech. Eng. Part B J. Eng. Manuf. (2014). doi:10.1177/0954405414539494.

[26] P. Rangaswamy, M.L. Griffith, M.B. Prime, T.M. Holden, R.B. Rogge, J.M. Edwards, R.J. Sebring, Residual stresses in LENS components using neutron diffraction and contour method, Mater. Sci. Eng. A. 399 (2005) 72-83. doi:10.1016/j.msea.2005.02.019.

[27] W. Zhang, Z. Feng, P. Crooker, Improved procedure for computing residual stresses from neutron diffraction data and its application to multipass dissimilar welds, Sci. Technol. Weld. Join. 16 (2011) 254-260. doi:10.1179/1362171810Y.0000000023.

[28] T. Gnäupel-Herold, P.C. Brand, H.J. Prask, Accessing the elastic properties of cubic materials with diffraction methods, in: Denver X-Ray Conf., 1998: pp. 464-470. doi:10.4028/www.scientific.net/MSF.278-281.151.

[29] W.A. Tayon, R.N. Shenoy, M.R. Redding, R. Keith Bird, R.A. Hafley, Correlation Between Microstructure and Mechanical Properties in an Inconel 718 Deposit Produced via Electron Beam Freeform Fabrication, J. Manuf. Sci. Eng. 136 (2014) 1-7. doi:10.1115/1.4028509.

[30] F. Roters, P. Elsenlohr, T.R. Bieler, D. Raabe, Macroscopic Examples, in: Cryst. Plast. Finite Elem. Methods Mater. Sci. Eng., Wiley-VCH, 2010: pp. 147-163.

[31] E. Clouet, G. Sebastien, H. Nuyen, M. Perez, C.S. Becquart, Dislocation interaction with $\mathrm{C}$ in a-Fe: A comparison between atomic simulations and elasticity theory, Acta Mater. 56 (2008) 3450-3460.

[32] T. Gnäupel-Herold, P.C. Brand, H.J. Prask, Calculation of Single-Crystal Elastic 
Constants for Cubic Crystal Symmetry from Powder Diffraction Data, J. Appl.

Crystallogr. 31 (1998) 929-935. doi:10.1107/S002188989800898X.

[33] G.A. Alers, J.R. Neighbours, H. Sato, Temperature dependent magnetic contributions to the high field elastic constants of nickel and an Fe-Ni alloy, J. Phys. Chem. Solids. 13 (1960) 40-55. doi:10.1016/0022-3697(60)90125-6.

[34] A. Kanrar, U.S. Ghosh, The variation of elastic constants of nickel-iron single crystal alloys from 78.76 to $300 \mathrm{~K}$, J. Phys. Chem. Solids. 44 (1983) 457-462.

[35] S. Matthies, H.G. Priesmeyer, M.R. Daymond, On the diffractive determination of singlecrystal elastic constants using polycrystalline samples, J. Appl. Crystallogr. 34 (2001) 585-601. doi:10.1107/S0021889801010482.

[36] E. Kröner, Berechnung der elastischen Konstanten des Vielkristalls aus den Konstanten des Einkristalls, Z. Phys. 151 (1958) 504-518.

[37] Z. Wang, T.A. Palmer, A.M. Beese, Effect of processing parameters on microstructure and tensile properties of austenitic stainless steel 304L made by directed energy deposition additive manufacturing, Acta Mater. 110 (2016) 226-235.

doi:10.1016/j.actamat.2016.03.019.

[38] B.E. Carroll, T.A. Palmer, A.M. Beese, Anisotropic tensile behavior of Ti-6Al-4V components fabricated with directed energy deposition additive manufacturing, Acta Mater. 87 (2015) 309-320. doi:10.1016/j.actamat.2014.12.054.

[39] A.M. Beese, B.E. Carroll, Review of Mechanical Properties of Ti-6Al-4V Made by LaserBased Additive Manufacturing Using Powder Feedstock, JOM. 68 (2015) 724-734. doi:10.1007/s11837-015-1759-z.

[40] D.D. Gu, W. Meiners, K. Wissenbach, R. Poprawe, Laser additive manufacturing of 
metallic components: materials, processes and mechanisms, Int. Mater. Rev. 57 (2012) 133-164. doi:10.1179/1743280411Y.0000000014.

[41] INCONEL ® alloy 625, Spec. Met. Corp. SMC-020. (2006). http://www.specialmetals.com/assets/documents/alloys/inconel/inconel-alloy-625lcf.pdf.

[42] A.M. Beese, Z. Wang, A.D. Stoica, D. Ma, Absence of dynamic strain aging in an additively manufactured nickel-base superalloy, "Submitted Publ. under Revis. (2016).

[43] L. Ferrer, B. Pieraggi, J.F. Uginet, Microstructural Evolution During Thermomechanical Processing of Alloy 625, in: Superalloys 718,625 Var. Deriv., 1991: pp. 217-228.

[44] S. Floreen, G.E. Fuchs, W.J. Yang, The Metallurgy of Alloy 625, in: Superalloys 718, 625, 706 Var. Deriv. Miner. Met. Mater. Socity, 1994: pp. 13-37. doi:10.7449/1994/Superalloys_1994_13_37.

[45] X.-L. Wang, T.M. Holden, G.Q. Rennich, A.D. Stoica, P.K. Liaw, H. Choo, C.R. Hubbard, VULCAN—The engineering diffractometer at the SNS, Phys. B Condens. Matter. 385-386 (2006) 673-675. doi:10.1016/j.physb.2006.06.103.

[46] K. An, H.D. Skorpenske, A.D. Stoica, D. Ma, X.L. Wang, E. Cakmak, First in situ lattice strains measurements under load at VULCAN, Metall. Mater. Trans. A Phys. Metall. Mater. Sci. 42 (2011) 95-99. doi:10.1007/s11661-010-0495-9.

[47] G.M. Stoica, A.D. Stoica, M.K. Miller, D. Ma, Temperature-dependent elastic anisotropy and mesoscale deformation in a nanostructured ferritic alloy, Nat. Commun. 5 (2014). doi:10.1038/ncomms6178.

[48] W. Voigt, Lehrbuch der Kristallphysik, Berlin-Leipzig: Teubner Verlag, 1928.

[49] A. Reuss, Berechnung der fliessgrenze von mischkristallen aufgrund der plastizitätsbedingung für einkristalle, Z. Angew. Math. Und Mech. 9 (1929) 49-58. 
[50] T. Gnäupel-Herold, A.A. Creuziger, M. Iadicola, A model for calculating diffraction elastic constants, J. Appl. Crystallogr. 45 (2012) 197-206. doi:10.1107/S0021889812002221.

[51] M.T. Hutchings, P.J. Withers, T.M. Holden, T. Lorentzen, Interpretation and Analysis of Lattice Strain Data, in: Taylor\&Francis (Ed.), Intronduction to Charact. Residual Stress by Neutron Diffr., 2005: pp. 213-240.

[52] R. De Wit, Diffraction elastic constants of a cubic polycrystal, J. Appl. Crystallogr. 30 (1997) 510-511. doi:10.1107/S0021889896012812.

[53] T.M. Holden, R.A. Holt, A.P. Clarke, Intergranular strains in Inconel-600 and the impact on interpreting stress fields in bent steam-generator tubing, Mater. Sci. Eng. A. 246 (1998) 180-198. doi:10.1016/S0921-5093(97)00732-6. 